\begin{tabular}{|l|l|l||}
\hline \multicolumn{2}{|c|}{ PublisherInfo } \\
\hline \hline PublisherName & $:$ & BioMed Central \\
\hline \hline PublisherLocation & $:$ & London \\
\hline \hline PublisherImprintName & $:$ & BioMed Central \\
\hline \hline
\end{tabular}

\title{
Break IT - The Breast Cancer Pathology Information Kit
}

\begin{tabular}{|l|l|l||}
\hline \multicolumn{2}{|c||}{ ArticleInfo } \\
\hline \hline ArticleID & $:$ & 3609 \\
\hline \hline ArticleDOI & $:$ & $10.1186 /$ bcr-1999-1-webreport0003 \\
\hline \hline ArticleCitationID & $:$ & 0003 \\
\hline \hline ArticleSequenceNumber & $:$ & 29 \\
\hline \hline ArticleCategory & $:$ & Web Report \\
\hline \hline ArticleFirstPage & $:$ & 1 \\
\hline \hline ArticleLastPage & $:$ & 3 \\
\hline \hline & $:$ & RegistrationDate : 1999-10-13 \\
ArticleHistory & $:$ & OnlineDate $\quad$ 1999-10-13 \\
\hline \hline ArticleCopyright & $:$ & Current Science Ltd1999 \\
\hline \hline ArticleGrants & $:$ & \\
\hline \hline ArticleContext & $:$ & 1305811 \\
\hline \hline
\end{tabular}




\section{Content}

Maintained by the Sustaining Oncological Studies (SOS) server. The site was launched in 1996 and is managed by the National Institute of Cancer Research, Genoa, Italy.

BreakIT or 'The BREAst cancer pathology information Kit - using offline and online 'Information Technologies' was established to aid professional training, support decision-making involved in the diagnosis and classification of breast cancer and acts as a common reference tool for pathologists worldwide.

Free access is available to the BreakIT NET 'repositories' which hold information aimed at practising pathologists, laboratory researchers, and others with an interest in breast cancer pathology. Content includes details of programmes offered by the European Commission, a comprehensive listing of international meetings and details of training and continuing education events. The 'journal' section provides links to publications on breast disease, plus a selection of titles and abstracts of relevant papers taken from PubMed which is updated quarterly.

The paid subscribers' area allows password-protected access to a 'virtual' case- study library and gives the opportunity to take part in online consultations.

\section{Content}

The simple navigation is hampered by slow connection, however the mirror site (http://www.breakit.org/) allows more efficient access from the UK. A number of broken links were found within the site, but the selection of annotated links to external pathology related websites are well chosen.

\section{Timeliness}

Updated in June 1999. 


\section{Evaluation}

This site offers a useful free service targeted to the European Breast Cancer Pathology community and gives paid members the opportunity to collaborate in the diagnosis of cases. However, the sluggishness can make the site frustrating to use.

\section{References}

1. Break IT. [http://sos.unige.it/breakit/index.html] 